\begin{abstract}
N.V. Mkrtchyan
National Research University Higher School of Economics; Institute for Social Analysis and Prediction, Russian Presidential Academy of National Economy and Public Administration, Moscow, Russia

Yu.F. Florinskaya

Institute for Social Analysis and Prediction, Russian Presidential Academy of National Economy and Public Administration; National Research University Higher School of Economics, Moscow, Russia
\end{abstract}

\title{
Labor Migration in Russia: International and Internal Aspects
}

\begin{abstract}
The authors examine the processes of internal and international labor migration in Russia. Available sources of statistical information and a survey of studies allow us to define them as quantitatively comparable, but having pronounced regional differences. Despite the gravitation of both internal and international migrants to the largest cities, Russian temporary labor migrants more often go to work in the regions of the North and the East of the country. Russians and foreign migrants complement each other in the regional labor markets rather than compete. The results of the recent research conducted by Institute for Social Analysis and Prediction Russian Presidential Academy of National Economy and Public Administration, used in the article, allow us to state that the social and economic effects of international and internal labor migration are similar. At the same time the significance of migration for the economy of households and local budgets in Russia is underestimated.
\end{abstract}

Keywords: labor migration, internal migrants, international migrants, regions of Russia.

JEL Classification: J61, R23.

\section{О.В. Синявская}

Институт социальной политики Национального исследовательского университета «Высшая школа экономики», Москва

Журнал НЭА, №1 (37), 2018, c. $193-203$

\section{С.С. Бирюкова}

Институт социальной политики Национального исследовательского университета «Высшая школа экономики», Москва

\section{Возможные меры снижения неформальной занятости и скрытой оплаты труда ${ }^{1}$}

Аннотация. Масштабы неформальной занятости и скрытой оплаты труда в России значительны и возрастали даже в условиях экономического роста и проведения налоговых реформ на протяжении 2000-х годов. Мировой опыт свидетельствует, что успехов в снижении масштабов неформальной занятости можно достичь только реализуя комплексную политику, охватывающую различные сферы регулирования, сочетающую стимулирующие и санкционные механизмы и включающую более широкие задачи по улучшению институтов, экономическим реформам, а также изменение социальных норм, связанных со снижением приемлемости неформальных отношений. На основе анализа особенностей и причин существования неформальной и теневой занятости в России в статье сформулированы рекомендации по снижению неформальной занятости и скрытой оплаты труда, учитывающие как мировой опыт, так и специфику причин неформальной занятости в России и те усилия, которые уже были предприняты российским правительством.

Ключевые слова: неформальная занятость, теневая занятость, скрытая оплата труда, налоговое регулирование, экономическое регулирование.

Классификация JEL: J46, J48.

\footnotetext{
${ }^{1}$ Работа, отдельные результаты которой представлены в настоящей статье, выполнена в рамках проекта «Содействие совершенствованию системы государственных финансов Российской Федерации», реализованного по заказу Минфина России.
} 


\section{Рекомендации для снижения}

неформальной занятости и скрытой оплаты труда в России

Проблема снижения неформальной занятости и скрытой оплаты труда волнует правительства стран с различным уровнем дохода, поскольку деформализация экономики сопряжена с рядом прямых и косвенных потерь (Andrews et al., 2011). Прямые потери связаны со снижением налоговых и страховых поступлений и, соответственно, с уменьшением возможностей государства финансировать программы развития, социального страхования и социальной поддержки; с расширением доли населения, ограниченного в трудовых и социальных правах и подверженного более высоким рискам бедности и социальной исключенности. Косвенные потери состоят в более низкой производительности труда в неформальной экономике и, как следствие, - ограниченным возможностям экономического рывка. Такие потери также связаны с неравными условиями конкуренции между предприятиями, включенными и не включенными в теневые экономические отношения. Таким образом, политика, направленная на снижение масштабов неформальной занятости и скрытой оплаты труда, важна не только с позиции фискальных или экономических интересов, но и для успешного социального развития общества.

Задача статьи - сформулировать рекомендации, направленные на снижение неформальной занятости и скрытой оплаты труда, релевантные российской действительности. В основу представленных ниже рекомендаций легли результаты, полученные авторами при обобщении мирового опыта эмпирических исследований неформальной занятости и экспертиза политики ее регулирования, а также результаты исследования неформальной и теневой занятости в России.

С точки зрения выработки политики важными особенностями российского рынка труда являются: 1) взаимная связанность между формальной, теневой и неформальной занятостью; 2) принципиальные различия между двумя сегментами неформальной занятости самозанятостью и занятостью по найму - как с точки зрения характеристик работников и их человеческого капитала, так и с точки зрения различий в мотивации участия в неформальной занятости; 3) рост неформальной занятости на протяжении последних 15 лет: главным образом, за счет спроса на неформальные услуги, предъявляемые населением - строительные, транспортные, бытовые, ухода за членами семьи; 4) мотивационная структура участия в неформальной занятости: с точки зрения работодателя - субъективно воспринимаемые как высокие трансакционные издержки (регистрации, отчетности и пр.), налоговые платежи, жесткость трудового законодательства, необходимость иметь средства для различных коррупционных поборов; с точки зрения работника - высокая ценность свободного графика, гибких условий труда для самозанятых, более высоких неформальных доходов - для всех неформально занятых, и, напротив, низкий уровень пенсий - его слабая связь с заработком, неудовлетворительное качество медицинских услуг - факторы, снижающие ценность формальной занятости.

Описанная выше специфика мотивов обусловливает необходимость применения следующих принципов в реализации политики снижения неформальной занятости и скрытой оплаты труда:

- комплексный характер политики;

- сочетание жесткого и мягкого подходов к снижению неформальной и теневой занятости: общих мер, направленных на улучшение институциональной среды; изменение социальных норм и конкретных мер, направленных на снижение неформальной занятости в определенных сферах инструментами налоговой политики, политики на рынке труда; административного регулирования;

- сочетание и сбалансированность стимулирующих и ужесточающих мер с акцентом на стимулы и предупреждение неформальной занятости;

- постепенность в реализации мер по снижению неформальной занятости и скрытой оплаты труда, отказ от идеи «быстрых побед» в этом направлении. 
Отталкиваясь от этих принципов и опираясь на существующие теоретические и эмпирические исследования, мы предлагаем принять меры по следующим ключевым направлениям: 1) стратегические - создание формальных рабочих мест, 2) экономические; 3) налоговые; 4) политики на рынке труда; 5) улучшение администрирования.

\section{Реализация комплексной стратегии} развития, направленной на увеличение числа формальных рабочих мест

Согласно результатам исследования, проведенного В.Е. Гимпельсоном и Р.И. Капелюшниковым, наблюдавшийся в последние десятилетия рост масштабов неформальной занятости был вызван не избыточно жестким регулированием российского рынка труда, а стабильно неудовлетворительным деловым климатом и слабыми практиками правоприменения, что можно считать «важным индикатором “институционального провала государства" (Gimpelson, Kapelyushnikov, 2014; Гимпельсон и др., 2017, с. 79). Следовательно, не меняя общую рамку экономической политики, не реформируя формальные институты с целью повышения доверия к государству, кардинально изменить масштабы неформальной занятости и скрытой оплаты труда невозможно. Все предлагаемые точечные меры дадут крайне ограниченный эффект.

Международный опыт свидетельствует о том, что в условиях институциональных проблем жесткие меры, осуществляемые путем высокоцентрализованного управления, надзора и мониторинга и направленные на ужесточение санкций за неформальную деятельность и скрытые платежи, оказываются менее әффективными, чем мягкие меры, направленные на создание стимулов формальной занятости и развитие внутреннего контроля у работодателей и работников, а также и всего общества в целом (Horodnic, 2016). Например, эмпирические исследования результативности мер снижения неформальной занятости и скрытой оплаты труда в Великобритании показали, что выгода от реализации кампании популяризации преимуществ полностью официальной работы составила 19 : 1 (прирост налоговых платежей в расчете на 1 ф. ст., потраченный на эту меру) по сравнению с отдачей от увеличения штрафов, которая составила 5 : 1 (Williams, 2009 , р. 16). Поэтому основу политики, направленной на снижение неформальной занятости и скрытой оплаты труда, должны составить инструменты так называемого мягкого регулирования. А именно:

- реализация комплексной стратегии развития, меняющей модель экономического развития, совершенствующей институциональную и деловую среду, повышающую качество регулирования, эффективность антикоррупционной деятельности, целью которой должно стать интенсивное создание формальных рабочих мест в экономике. Сохранение высокого уровня недоверия государству и его неспособность снизить уровень коррупции препятствуют изменению отношения работодателей и работников к уплате налогов и страховых платежей и обесценивают әффекты других мер снижения скрытой оплаты труда (Horodnic, 2016). Более того, исключительно репрессивные методы без преодоления основополагающих причин теневой экономики приводят к снижению экономической активности в целом за счет сокращения объема теневой экономики без соответствующего увеличения формальной (Krstić et al., 2013);

- разработка и реализация мер, направленных на модернизацию государственного управления, в том числе: повышение процессуальной прозрачности и справедливости (с целью повышения уверенности работодателей и работников в понятности и прозрачности налоговых процедур и в том, что в налоговых органах к ним будут относиться к уважением и беспристрастностью) и содействие процессуальному правосудию (в части восприятия работодателями и работниками справедливости и равенства их вклада в уплату налогов и социальных платежей - в частности, посредством повышения доли работников в финансировании страховых взносов);

- создание условий, позволяющих повысить качество предоставляемых государством услуг, в том числе в сфере социальной 
поддержки населения - фактор, повышающий в глазах населения ценность формальной занятости и важность уплаты налогов и взносов на социальное и пенсионное страхование. С точки зрения снижения масштабов скрытой оплаты труда крайне важно содействовать повышению так называемой перераспределительной справедливости (чтобы работодатели и работники ощущали, что получают товары и услуги того качества, которое соответствует их налоговым и социальным платежам). Недавние исследования в странах ЦВЕ показали, что масштабы выплат в конвертах ниже в странах с меньшим неравенством в доходах, более әффективным перераспределением через систему социальных трансфертов и более активной политикой государства на рынке труда, направленной на защиту наиболее уязвимых групп (Horodnic, 2016 , p. 8). Результаты данного исследования также свидетельствуют о том, что недовольство уравнительным характером российской пенсионной системы - один из важных мотивов участвовать в скрытой оплате труда со стороны работников. Таким образом, повышение связи между страховыми пенсионными взносами и размером пенсий может выступать фактором, усиливающим желание работников получать белую заработную плату;

- реализация комплекса мер, направленных на повышение качества человеческого капитала трудоспособного населения страны, поскольку, с одной стороны, имеются свидетельства более высоких рисков неформальной занятости у лиц с низкими уровнями образования, а с другой, мировой опыт свидетельствует о более низких масштабах неформальной занятости в странах с высокими показателями человеческого капитала;

- разработка и реализация социальной кампании, направленной на популяризацию формальной занятости и повышение озабоченности негативными последствиями неформальной занятости и скрытой оплаты труда. Элементы әтой кампании могут включать:

- разъяснительную работу с населением по дискредитации неформальной экономической деятельности: показывающую криминальную основу неформальной деятельности, представляющую компании, уклоняющиеся от уплаты налогов или использующие неформальный труд как меньшинство, ущемляющее интересы большинства, подрывающие экономические и социальные основы существования государства, ухудшающие социальную защищенность всего населения. Для повышения әффективности таких кампаний, особенно на первых порах, их целесообразно проводить для отдельных категорий населения (например, молодежи) и сфер деятельности (наиболее популярных у населения - например, торговля, строительство, бытовые услуги);

- образовательные программы для населения и работодателей по основам государственных финансов: разъяснение принципов налоговой политики, целей, на которые поступают налоги, связи налогов и общественных выгод, всего того, как неформальная занятость и скрытая оплата труда негативно влияют на уровень пенсий и пр. Программы разъяснения принципов работы пенсионной системы и пенсионной формулы также могут помочь лучшему пониманию людьми связи между скрытой оплатой труда и размерами их будущих пенсий.

Отдача от перечисленных выше мер не будет очень быстрой. Тем не менее отказ от этой компоненты политики поставит под сомнение әффективность реализации более конкретных шагов, связанных с профилактикой конкретных форм неформальной занятости или ужесточением наказания за такую практику.

\section{Меры экономического регулирования, направленные на снижение неформальной занятости \\ Во всех странах улучшение условий} ведения бизнеса и инвестиционного климата является одним из краеугольных камней политики, направленной на снижение неформальной занятости и скрытой оплаты труда. 
Меры стимулирующего характера, содействующие легализации существующей неформальной занятости и предупреждающие ее расширение, должны прежде всего быть направлены на снижение административных барьеров; они должны облегчить вход в легальный бизнес, стимулировать создание новых и расширение действующих предприятий. Несмотря на то что в последние годы российскому правительству удалось значительно продвинуться по пути упрощения процедур и снижения сроков и стоимости регистрации индивидуальных предпринимателей и малого бизнеса, бюрократическая нагрузка и административное давление по-прежнему воспринимаются предпринимательским сообществом как весомые барьеры ведению легального бизнеса.

Поскольку основной рост неформальной занятости в последние десятилетия происходил в сфере оказания услуг населению, стимулирование формальной занятости можно осуществлять через влияние на спрос на эти услуги. В частности, можно рекомендовать такие процедуры легализации сферы услуг, как:

- развитие платформ сервисов (по аналогии с уже существующими в различных регионах службами транспортных посредников например, Yandex.Taxi и др., развивающимися в Москве платформами услуг мелкого ремонта, кратковременного присмотра за детьми например, Kidsout) для оказания максимально широкого перечня персональных и бытовых услуг во всех российских регионах;

- внедрение на базе платформ безналичного расчета за предоставляемые услуги - либо посредством онлайн-платежей, либо с использованием банковских карточек, что будет способствовать уменьшению нелегального наличного оборота и тем самым создавать условия для расширения формальной занятости;

- создание на базе таких платформ регистров, прошедших какую-то минимальную проверку поставщиков услуг - самозанятых. Это особенно важно в сфере персональных социальных услуг, где огромную роль играет доверие между заказчиком и исполнителем. Например, расширению спроса на услуги нянь и повышению легализации этого сегмента услуг могло бы содействовать формирование регистра нянь, получивших государственную лицензию на оказание таких услуг, какие существуют, например, во Франции;

- можно рассмотреть также введение ваучеров на персональные услуги определенного типа и/или определенным группам населения по аналогии с существующими в России и других странах практиками социальных ваучеров, инновационных ваучеров. Поставщиками услуг по ваучерам могут выступать только зарегистрированные компании / индивидуальные предприниматели. Похожая программа реализуется, например, во Франции (Eurofound, 2008).

\section{Меры налогового регулирования}

Избыточное налоговое бремя часто фигурирует в опросах предпринимателей как фактор, препятствующий их легальной деятельности ${ }^{2}$, известны также отдельные работы, показывающие положительное влияние налоговой реформы 2001 г. на сокращение масштабов неформальной занятости (Slonimczyk, 2011). Но, на наш взгляд, возможности применения инструментов налогового характера, направленные на сокращение российской неформальной занятости, практически исчерпаны. Дальнейшее снижение тарифов социальных (включая пенсионные) взносов скорее всего не только не приведет к расширению налогооблагаемой базы, но еще больше сократит страховые поступления во внебюджетные фонды, как это уже продемонстрировала реформа 2005 г. Если не компенсировать тем или иным образом потерю доходов внебюджетных фондов, это негативно скажется на уровне пенсионных выплат, качестве и доступности медицинских услуг. Между тем претензии к государственным услугам и сейчас - весомый барьер на пути формализации

\footnotetext{
${ }^{2}$ См., например, результаты опросов 2008-2017 гг. ВЦИОИ и 2017 г. Бизнес-школы Сколково, представленные на сайте КРОО «СП» в материале «Предпринимательство в России: доверие, барьеры и факторы успеха» от 16.10.2017 (http://kroosp.ru/predprinimatelstvo-v-rossii-doverie-barery-i-faktory-uspeha/).
} 
занятости. Кроме того, предоставлять налоговые скидки и льготы самозанятым, в настоящее время находящимся вне видимой части экономики, бессмысленно: статус-кво для этих работников таков, что текущей альтернативой является отсутствие каких-либо налоговых отчислений, поэтому любой льготный режим по факту будет обозначать для них рост издержек на ведение экономической деятельности в перспективе.

Снижение ставок налогов или тарифов страховых взносов для низкооплачиваемых категорий занятых либо повышение необлагаемого подоходным налогом уровня доходов, применяемое в ряде развитых европейских стран, также вряд ли оправданно. В условиях слабой правоприменительной практики и высокого социального одобрения теневых отношений эти меры могут только дополнительно стимулировать расширение сегмента скрытой оплаты труда.

Поэтому единственным инструментом налогового регулирования, который можно использовать для легализации деятельности самозанятого населения, остается внедрение авансовых платежей по НДФЛ в фиксированном размере для лиц, не имеющих легального статуса индивидуального предпринимателя. Эта мера, не решая проблемы неполного охвата трудоспособного населения программами социального страхования, тем не менее способна расширить базу по уплате НДФЛ и соответствующие налоговые отчисления, а также легализовать часть нерегистрируемой самозанятости. Для лиц, осуществляющих такую деятельность, возможность авансовых платежей по НДФЛ облегчила бы возможности получения кредитов, оформления виз и одновременно позволила бы им претендовать на получение вычетов НДФЛ.

Стимулирующие меры для регистрации самозанятых неналогового характера создавать условия, в которых возложенные налоговые расходы в результате раскрытия информации о доходах будут компенсироваться какими-либо выгодами, отложенными или текущими. В российских условиях при низком уровне доверия к государству, особенно на длинном горизонте планирования, текущие выгоды являются более предпочтительными. Они могут лежать в сферах пенсионного обеспечения, медицинского обслуживания, банковского сектора или сферы социальных услуг и социальной поддержки.

В сфере социальной поддержки в настоящее время имеет место движение в сторону условных трансфертов, повышения адресности и развития социального контракта. Последний, преследуя цель вывода граждан на самообеспечение в средне- или долгосрочной перспективе, как правило, включает создание условий для занятости населения. Наличие оплачиваемой занятости по найму или иной приносящей доход официально оформленной трудовой деятельности может быть условием предоставления доступа к отдельным социальным программам. В частности, пособия по бедности - для семей с детьми или универсальные для всего населения - могут предоставляться при условии занятости всех трудоспособных членов домашних хозяйств. Если такие программы будут реализованы, они могут стать стимулом для выхода части самозанятых в видимый сегмент экономики, в том случае если размеры выплат в рамках социальных программ будут достаточно существенными, такими, что смогут перекрывать потери домашних хозяйств от выплаты налогов.

Наряду с этим в рамках пенсионной системы можно предложить модификацию активно используемой в развивающихся странах с большим неформальным сектором схемы «matching defined contribution» (схема с согласованными установленными взносами). В первоначальном виде идея этой схемы направлена на расширение охвата населения пенсионным обеспечением в условиях высоких уровней неформальной занятости и аналогична идее авансовых платежей по НДФЛ. Так, самозанятые граждане, работающие без оформления статуса индивидуального предпринимателя, получают право регулярно (периодичность определяется условиями программы) вносить взносы в некотором фиксированном (или сверх него) размере на свой индивидуальный пенсионный счет. Как правило, такие про- 
граммы действуют на накопительных принципах финансирования, но их можно организовать и на распределительных принципах.

В российских условиях, где масштабы неформальности намного ниже, можно использовать в двух вариантах: первый - аналогично авансовым платежам по НДФЛ и применению этой практики в развивающихся странах можно разрешить самозанятым, не имеющим регистрации, осуществлять такие платежи на свои индивидуальные пенсионные счета. Это позволит решить проблему отсутствия у неформально занятого населения пенсионных прав, помимо права на социальную пенсию по старости. Вместе с тем, учитывая низкую ценность для российского населения длинных денег, неготовность ущемлять текущее потребление в интересах будущих доходов, получение которых отложено на отдаленную перспективу, можно предложить рассмотреть более затратный, но, по-видимому, более эффективный метод расширения охвата самозанятого населения пенсионными программами и снижения неформальной занятости. Например, для самозанятых, решивших легализовать свою деятельность и получить статус индивидуального предпринимателя, можно предложить участие в уплате фиксированного размера пенсионных взносов (на действующем или более высоком уровне) при одновременном субсидировании этих взносов со стороны государства (по аналогии с действовавшей ранее программой государственного софинансирования пенсионных взносов населения). Условия государственного участия в этой программе можно просчитать в рамках пенсионного моделирования.

Интересный пример сочетания мер налогового и трудового регулирования персональных услуг по дому, направленных на их формализацию, дает опыт Польши. Там была введена система налоговых вычетов на услуги домашнего персонала (например, мелкий ремонт, уборка) для населения. Одновременно возможность получить такую работу предоставляется безработным через службы занятости на условиях социального контракта. При этом устанавливается условие: работу не могут получить близкие родственники, инвалиды
(Eurofound, 2008). Система 50\%-ной субсидии на оплату легальных услуг ремонта жилья, аналогичная налоговым вычетам в Польше, введена в Швеции (Eurofound, 2008). В обеих странах эти меры показали свою әффективность. В Испании и Австрии налоговые вычеты/субсидии введены на оплату официально оказанных частных услуг ухода за пожилыми и инвалидами (Eurofound, 2008). Можно предложить продумать и реализовать в России меры, аналогичные европейскому опыту: сочетание мер налогового и трудового регулирования в части услуг домашнего персонала и ухода за детьми, престарелыми и инвалидами, которые, как показывают обследования населения, в настоящее время в основном оказываются на неформальной основе.

\section{Регулирование трудовых отношений, меры политики на рынке труда}

Одна из весомых причин существования неформальной занятости в России связана с недостаточной гибкостью рынка труда, а именно - с ограниченным предложением формальных рабочих мест с дистанционной и неполной занятостью, гибкими часами работы, позволяющими людям совмещать занятость с выполнением семейных обязанностей. На дефицит таких мест особенно жалуются женщины - с маленькими детьми, предпенсионного и пенсионного возраста. Другой фактор, влияющий на выбор неформальной занятости, связан с существованием дискриминации, гендерных и возрастных стереотипов, затрудняющих формальное трудоустройство женщин с детьми и лиц старших (зачастую старше 40-45 лет) возрастов.

Соответственно, меры стимулирующего и превентивного характера в сфере занятости могут включать, с одной стороны, содействие появлению в формальном сегменте новых форм занятости, расширение возможностей гибкой и дистанционной занятости. С другой стороны, очевидно, требуется расширение возможностей повышения квалификации и переобучения групп населения, имеющих уязвимые позиции в получении формальной занятости. 
Данные выборочных обследований показывают, что теневая занятость получает максимальное распространение среди наиболее молодых работников. При этом создается ситуация, при которой молодые работники получают свой первый опыт занятости на условиях неофициального найма либо официального найма с частичным сокрытием дохода. Такая траектория входа на рынок труда формирует толерантное отношение к теневой занятости и теневым доходам у населения и может существенно влиять на дальнейшее поведение работников.

Следовательно, возможным направлением деятельности, направленной на сокращение распространения таких практик, может стать политика содействия официальному трудоустройству учащихся и выпускников, в том числе:

- развитие сотрудничества между учебными заведениями и профильными работодателями,

- создание системы официальных стажировок студентов с возможностью дальнейшего трудоустройства по окончании учебы,

- создание базы рабочих мест для специалистов без опыта работы,

- частичный возврат к практике распределения работников узкого профиля.

Среди мер санкционного характера можно рекомендовать:

- усилить полномочия инспекций Роструда и предоставить им возможности проводить совместные с ФНС внеплановые проверки предприятий в случае поступления жалоб о неформальном найме или выплате заработной платы в конвертах;

- предоставить право внеплановых проверок предприятий представителям Роструда и ФНС по фактам поступления жалоб от безработных граждан, которые до этого были неформально занятыми. Это требует усиления межведомственного взаимодействия между службами занятости, Рострудом и ФНС;

- рекомендовать проводить регулярные проверки предприятий, работающих в сферах с повышенными рисками неформальной занятости, поскольку исследования показывают четкую связь между распространенностью неформальной занятости и теневых отношений с определенными видами экономической деятельности (строительство, торговля, сфера обслуживания населения) и размером предприятий. Например, в Нидерландах трудовые инспекции проводят специальные адресные проверки в секторах с повышенными рисками неформальной и теневой занятости, к которым относится, в частности, строительство (Cremers, 2017). В Эстонии в 2012 г. внеплановые проверки строительных организаций проводились силами налоговых инспекций (Cremers, 2017).

\section{Меры, направленные на улучшение администрирования}

Наряду с отмеченной выше необходимостью повышать качество государственных услуг и уровень социальных выплат, усиливать связь между выплатами по социальному страхованию и взносами стимулирующие меры в области администрирования могут включать использование выгод информационной экономики - например расширение возможностей электронной регистрации, электронного обмена данными, электронных платежей и пр.

Санкционные механизмы в российских условиях распространены в большей степени, чем стимулирующие, однако их эффективность напрямую зависит от эффективности системы контроля и выявления случаев нарушения институциональных правил и законов. Набор санкционных мер административного характера может включать два основных направления: связанное с улучшением выявления случаев неформальной занятости и направленное на уменьшение оборота наличных платежей в әкономике.

С целью улучшения выявления неформальной занятости можно рекомендовать следующие меры: 
- улучшение межведомственного взаимодействия и налаживание информационного обмена между структурами, имеющими возможность выявлять нарушения в сфере регистрации трудовых отношений, уплаты страховых и налоговых платежей (ФНС, ПФР, ФОМС, ФМС, Роструд, службы занятости);

- налаживание единой информационной системы, введение единого номера идентификации личности либо установление корреспонденции между существующими идентификаторами (ИНН, СНИЛС, паспорт) с целью выявления нарушений в уплате налогов или страховых взносов;

- создание реестра организаций, использующих неформальную или теневую занятость, по аналогии с реестром недобросовестных поставщиков, и введение ограничений на участие таких организаций в государственных тендерах.

Результаты исследования эффективности применения перечисленных выше мер в странах ЕС показывают, что большинство (от 70 до 80\%) заинтересованных сторон оценивает их преимущественно как высоко эффективные (Eurofound, 2013).

С целью стимулирования безналичного оборота и борьбы с обналичиванием у населения можно рекомендовать популяризацию и создание максимально привлекательных для потребителей банковских продуктов - платежных карт, предполагающих возможность осуществления платежей через Интернет, со смартфонов, связанных с накоплением бонусов, баллов, возможностью получения скидок или обмена баллов на какие-то товары или услуги, схем кэш-бэк и др.

Одним из механизмов санкционного характера, направленных на население, может стать контроль источников доходов при совершении крупных покупок - например, необходимость указать источник средств при единовременных потребительских тратах на сумму свыше 100 тыс. руб. В такие траты попадут все покупки недвижимого имущества, автомобилей, некоторых потребительских товаров длительного пользования, товаров роскоши. Подтверждение доходов - справка о доходах с места работы для наемных работников либо сведения о доходах и прибыли для индивидуальных предпринимателей или самозанятых. Однако здесь потребуются сложные механизмы оценки потребительских возможностей граждан с разным уровнем доходов, исследования сберегательного поведения.

\section{ЛИТЕРАТУРА}

Гимпельсон В.Е., Зудина А.А., Капелюшников Р.И., Лукьянова А.Л., Ощепков А.Ю., Рощин С.Ю., Смирных Л.И., Травкин П.В., Шарунина А.В. (2017). Российский рынок труда: тенденции, институты, структурные изменения. Гимпельсон В.Е., Капелюшников Р.И., Рощин С.Ю. (общ. ред.). [Электронный pecypc] Режим доступа: https://csr.ru/ wp-content/uploads/2017/03/Doklad_ trud.pdf, свободный. Загл. с экрана. Яз. рус. (дата обращения: январь 2018 г.).

Andrews D., Sánchez A.C., Johansson Å. (2011). Towards a Better Understanding of the Informal Economy. OECD Economics Department Working Papers, No. 873, OECD Publishing. [Электронный pecypc] Режим доступа: http://dx. doi.org/10.1787/5kgb1mf88x28-en, свободный. Загл. с экрана. Яз. англ. (дата обращения: январь 2018 г.).

Cremers J. (2017). Undeclared Work in the Construction Industry: Background Paper. European Platform Undeclared Work: Construction Seminar. Conference Paper. Tilburg University, Department of Labour Law and Social Policy. [Электронный pecypc] Режим доступа: https://www. tilburguniversity.edu/upload/8d7669c73af6-49f3-a602-365511c78db9_Background Paper-ConstructionSeminar-3May17.pdf, свободный. Загл. с экрана. Яз. англ. (дата обращения: январь 2018 г.).

Eurofound (2008). Measures to Tackle Undeclared Work in the European Union. Dublin: Eurofound. 
Eurofound (2013). Tackling Undeclared Work in 27 European Union Member States and Norway: Approaches and Measures Since 2008. Dublin: Eurofound.

Gimpelson V., Kapeliushnikov R. (2014). Between Light and Shadow: Informality in the Russian Labour Market, IZA DP No. 8279.

Horodnic I.A. (2016). Cash Wage Payments in Transition Economies: Consequences of Envelope Wages. IZA World of Labor. [Электронный pecypc] Режим доступа: https://wol.iza. org / articles / cash-wage-payments-in-transition-economies-consequences-of-envelope-wages /long, свободный. Загл. с экрана. Яз. англ. (дата обращения: январь 2018 г.).

Krstić G., Schneider F., Arandarenko M., Arsić M., Radulović B., Ranđelović S., Janković I. (2013). The Shadow Economy in Serbia: New Findings and Recommendations. Belgrade: Foundation for Advancement of Economics and USAID Study.

Slonimczyk F. (2011). The Effect of Taxation on Informal Employment. HSE \& MPRA Working Paper.

Williams C.C. (2009). The Prevalence of Envelope Wages in Former Soviet Baltic States // Baltic Journal of Management. Vol. 4. No. 3. P. 288-300.

Поступила в редакиию 9 февраля 2018 года

\section{REFERENCES}

(with English translation or transliteration)

Andrews D., Sánchez A.C., Johansson Å. (2011). Towards a Better Understanding of the Informal Economy. OECD Economics Department Working Papers, No. 873, OECD Publishing. Available at: http:// dx.doi.org/10.1787/5kgb1mf88x28-en (accessed: January 2018).

Cremers J. (2017). Undeclared Work in the Construction Industry: Background Paper. European Platform Undeclared Work: Construction Seminar. Conference Paper. Tilburg University, Department of Labour Law and Social Policy. Available at: https://www.tilburguniversity. edu/upload/8d7669c7-3af6-49f3-a602365511c78db9_BackgroundPaper-ConstructionSeminar-3May17.pdf (accessed: January 2018).

Eurofound (2008). Measures to Tackle Undeclared Work in the European Union. Dublin: Eurofound.

Eurofound (2013). Tackling Undeclared Work in 27 European Union Member States and Norway: Approaches and Measures Since 2008. Dublin: Eurofound.

Gimpelson V., Kapeliushnikov R. (2014). Between Light and Shadow: Informality in the Russian Labour Market, IZA DP No. 8279 .

Gimpelson V.E., Zudina A.A., Kapelyushnikov R.I., Lukyanova A.L., Oschepkov A.Yu., Roshchin S.Yu., Smirnyh L.I., Travkin P.V., Sharunina A.V. (2017). The Russian Labor Market: Trends, Institutions, Structural Changes. Gimpelson V.Ye., Kapelyushnikov R.I., Roshchin S.Yu. (eds). Available at: https://csr.ru/wp-content/ uploads/2017/03/Doklad_trud.pdf (accessed: January 2018, in Russian).

Horodnic I.A. (2016). Cash Wage Payments in Transition Economies: Consequences of Envelope Wages. IZA World of Labor. Available at: https://wol.iza.org/articles/ cash-wage-payments-in-transition-economies-consequences-of-envelope-wages / long (accessed: January 2018).

Krstić G., Schneider F., Arandarenko M., Arsić M., Radulović B., Ranđelović S., Janković I. (2013). The Shadow Economy in Serbia: New Findings and Recommendations. Belgrade: Foundation for Advancement of Economics and USAID Study.

Slonimczyk F. (2011). The Effect of Taxation on Informal Employment. HSE \& MPRA Working Paper.

Williams C.C. (2009). The Prevalence of Envelope Wages in Former Soviet Baltic States. Baltic Journal of Management, 4, 3, 288-300. 


\title{
O.V. Sinyavskaya
}

Institute for Social Policy, National Research University - Higher School of Economics Moscow, Russia

\section{S.S. Biryukova}

Institute for Social Policy, National Research University - Higher School of Economics Moscow, Russia

\section{Possible Measures Aimed at Reducing Informal Employment and Hidden Wages}

Abstract. The scale of informal employment and hidden wages in Russia is significant and has increased even under conditions of economic growth and tax reforms throughout the 2000s. International experience proves that success in reducing the level of informal employment can only be achieved by implementing a comprehensive policy that combines incentives and sanctions in various spheres of regulation and includes broader tasks for improving institutions, economic reforms, and changing social norms related to relevance of informal relations. Within the framework of the study, based on an analysis of the specifics and causes of the existence of informal and shadow employment in Russia, authors formulate recommendations aimed at reducing informal employment and hidden wages. Recommendations take into account relevant international experience, as well as the specifics of the causes of informal employment in Russia and policies already undertaken by the Russian government.

Keywords: informal employment, shadow employment, hidden wages, tax regulation, economic regulation. JEL Classification: J46, J48.

\author{
Е.Т. Гурвич \\ Экономическая экспертная группа, НИФИ, Москва \\ Е.С. Вакуленко \\ НИУ ВШЭ, Москва
}

\section{Исследования российского рынка труда}

\section{и экономическая политика}

Аннотация. В статье обобщаются результаты работ, посвященных изучению механизмов российского рынка труда. Рассматривается формирование безработицы и оплаты труда, связь показателей рынка труда с инфляцией и адаптация рынка труда к шокам. Показано, что российский рынок труда отличается высокой гибкостью, о чем свидетельствует, в частности, последовательное снижение естественного уровня безработицы (NAIRU), большая эластичность реальной заработной платы по безработице и быстрое восстановление полной занятости после негативных внешних шоков. Выделены проблемы на российском рынке труда, которые в ближайшие годы могут стать важнейшим ограничением экономического роста (в частности, сокращение численности рабочей силы и рост доли оплаты труда в ВВП), если не будут приняты действенные меры, опирающиеся на результаты ранее проведенных и новых научных исследований.

Ключевые слова: российская экономика, рынок труда, гибкость реальнй заработной платы, адаптаиия к шокам.

Классификация JEL: E24, J08, O57.

Формирование безработицы

Значительную часть показателей, играющих ключевую роль при формировании макроэкономической политики, составляют различные характеристики рынка труда - прежде всего безработица и заработная плата.

\footnotetext{
${ }^{3}$ The work, some of the results of which are presented in this article, was carried out within the framework of the project "Development of the system of public finances of the Russian Federation", implemented by the order of the Ministry of Finance of Russia.
} 